\title{
A Cidade e a História dos Jovens: Em busca das Heterotopias
}

Leonardo Brandão*

Este artigo tem por objetivo relacionar a noção de heterotopia, tal como proposta pelo filósofo Michel Foucault, com o momento de emergência dos jovens adeptos do skate de rua (street skate) durante a década de 1980 no Brasil. Para tanto, utiliza-se como fonte revistas especializadas nesta atividade, publicadas durante o período em questão, para analisar a maneira com que muitos jovens fizeram uso de seus corpos no espaço urbano de grandes e médias cidades. Constatou-se que, nesta época, havia uma influência do punk sobre a atividade do skate, sendo que para os skatistas, as ruas podiam oferecer muito mais do que um espaço de locomoção, sendo interpretadas como lugares de diversão, desafio e/ou entretenimento. Trata-se de pensar a cidade revelando espaços de enunciações subjetivas até então desconhecidas.

Palavras-chave: Heterotopia; Skate; Juventude.

This paper aims to relate the notion of heterotopia, as proposed by the philosopher Michel Foucault, with the moment of emergence of young fans of street skating during the 1980s in
Considerações

iniciais

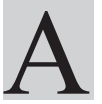
noção de "heterotopia" apareceu pela primeira vez nos escritos do filósofo francês Michel Foucault, e de forma muito breve, no livro "As palavras e as coisas", publicado inicialmente na França no ano de 1966. No entanto, foi somente a partir de uma Conferência ao Círculo de Estudos Arquiteturais de Paris, proferida em março de 1967 (e publicada posteriormente no Brasil com o título de “Outros Espaços”), que o filósofo forneceu a essa noção algum estofo teórico e operacionalidade.

\footnotetext{
* Doutor em História Social pela PUC/SP. brandaoleonardo@uol.com.br
} 
Brazil. For this purpose, is used as source magazines in this activity, published during the period in question, to analyze the way that many young people made use of their bodies in urban areas of large and medium cities. It was noted that at this time, punk was an influence on the activity of skateboarding, and for the skaters, the streets could offer much more than a space of movement, are interpreted as places of fun, challenge and / or entertainment. It is thought the city spaces revealing hitherto unknown subjective utterances.

Keywords: Heterotopia, Skateboard, Youth.

Ao analisar a questão da heterotopia em Michel Foucault, Rodrigo Valverde, professor do Departamento de Geografia da USP, afirmou que um dos propósitos do filósofo fora o de trabalhar com uma forma de concepção espacial que valorizasse a "presença de múltiplas representações conflitantes em uma mesma área"1. De fato, Foucault afirma que "a heterotopia tem o poder de justapor em um só lugar real vários espaços, vários posicionamentos que são em si próprios incompatíveis"2. Nesse sentido, a virtude de tal noção estaria em nos induzir a uma compreensão mais complexa e heterogênea do espaço, permitindo-nos apontar a existência de percepções que fugiriam da racionalidade instrumental moderna. Para Foucault, portanto, existiriam certos espaços que, em função da movimentação de atores e de seus significados, poderiam ser pensados como espaços de inversão, suspensão ou neutralização da ordem oficial.

Mas seria possível aproximarmos a noção de heterotopia dos estudos históricos? Cremos que sim, e um exemplo concreto pode estar no experimentalismo estético/espacial que muitos jovens adeptos do street skate passaram a realizar em meados da década de 1980 no Brasil.

O skate, assim como outras práticas corporais, apresenta um polimorfismo bastante evidente. A sua prática em pistas e campeonatos possui certas diferenças em relação à que é exercida nas ruas (street). Se, por um lado, as modalidades

${ }^{1}$ VALVERDE, Rodrigo. Sobre espaço público e heterotopia. In: Geosul. Florianópolis, v. 24, n. 48, 2009, p. 10.

${ }^{2}$ FOUCAULT, Michel. Outros Espaços. In: Ditos e Escritos (v. III). Estética: Literatura e pintura, música e cinema. Rio de Janeiro: Forense Universitária, 2009, p. 418.

${ }^{3}$ De acordo com o antropólogo Giancarlo Machado, "a modalidade street skate, como o próprio nome sugere, possui como objetivo central a prática do skate nas ruas da cidade. Entretanto, pratica skate nas ruas não significa dizer que os skatistas, munidos de seus 'carrinhos', circulem por aí dando somente impulsos em asfaltos e calçadas, por entre pedestres, carros, motos, caminhões e outros veículos. Ao contrário, eles transitam e interagem com a dinâmica urbana tendo em vista a procura por 'picos', isto é, equipamentos urbanos dotados de certas características que possibilitam a prática do street skate", In MACHADO, Giancarlo Marques Carraro. De "carrinho" pela cidade: a prática do street skate em São Paulo. Dissertação (Mestrado em Antropologia), USP, 2011, p. 23. 
do universo do skate praticadas somente em rampas (como o vertical e o big air) são espetacularizadas e exibidas como atividades esportivas (e "radicais") em canais de televisão aberta; por outro, a praticada em equipamentos urbanos (corrimãos, bancos, escadas, etc.), ao contrário, revela características distintas e com pouca relação de identificação com o esporte moderno.

Neste artigo, trataremos especificamente do skate praticado nas ruas, conhecido como street skate. E embora essa atividade tenha sido introduzida no país no final da década de $1960^{4}$, foi somente em meados da década de 1980 que ela passou a ser realizada, para além das ruas e calçadas, também sobre escadas, buracos, muretas, corrimãos etc ${ }^{5}$.

Este novo uso do skate engendrava uma forma de ver e utilizar o espaço que não era o previsto nem o aceitável institucionalmente. Pois fazer de um corrimão um obstáculo e não um instrumento de ajuda para apoiar o corpo, usar escadas para saltos e não como um auxílio para se passar de um nível ao outro do pavimento são exemplos concretos, reais e localizáveis de heterotopias; isto é, de invenção de outros espaços dentro dos próprios espaços.

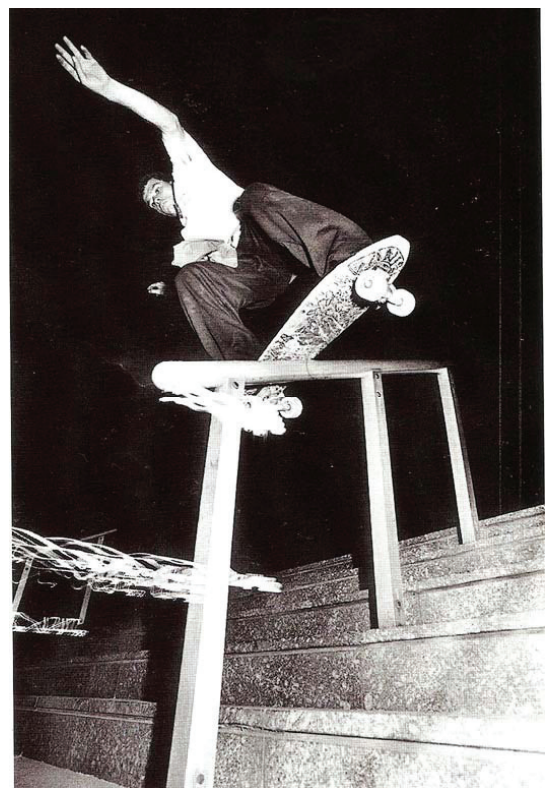

${ }^{4}$ BRANDÃO, Leonardo. O surfe de asfalto: a década de 1970 e os momentos iniciais da prática do skate no Brasil. In: Brandão, Leonardo; HONORATO, Tony (org.). Skate \& Skatistas: questões contemporâneas. Londrina: UEL, 2012, p. 20.

${ }^{5}$ BRANDÃO, Leonardo. A cidade e a tribo skatista: juventude, cotidiano e práticas corporais na história cultural. Dourados: EDUFGD, 2011, p. 103. 
Skatista em São Paulo descendo um corrimão na rua em 1988. Fonte: BRITTO, E. (org.). A Onda Dura: 3 Décadas de Skate no Brasil. São Paulo: Parada Inglesa, 2000, p. 30.

A questão, entretanto, é que as heterotopias geram inquietações: um corrimão não é mais um corrimão, nem uma escada é tão somente uma escada. Além disso, não podemos nos esquecer da grande heterotopia citada por Foucault: o navio, figura por excelência do século XIX, o navio inglês nos mares, por exemplo, o navio transatlântico... Pedaço grande de espaço que flutua no imenso mar. Mas neste caso em particular, parece que a heterotopia também pode ser a própria prancha de skate, minúsculo pedaço de espaço - comparado com o navio - mais leve que ele, certamente, metáfora do que se passa no século XX e não mais no XIX. Em Foucault há vários tipos de heterotopias: abertas, fechadas, menores, maiores, umas que parecem fascistas, outras não... Todas são espaços que incluem dentro deles vários espaços que seriam incompatíveis. Mas o street skate é interessante porque é um espaço que literalmente corre, sai do lugar, não tem lugar e é da sua essência não ter um. O skate corre sobre os espaços da cidade e é um objeto ao mesmo tempo próprio (do skatista) e exposto a todos. É um solo constantemente deslocalizado, um lugar sem lugar (porque se ele tiver um lugar já deixa de ser o que é). Diferente do navio, um espaço fechado dentro de outro, que oferece conforto, luxo e segurança, o skate seria uma heterotopia mesmo da insegurança, do mínimo necessário, da raridade das coisas para se apoiar, do espaço rarefeito.... O skate reenvia a imaginação ao tempo dos primeiros barqueiros, que não tinham nada a não ser um pinguelinha de barco, prestes sempre a virar. Reenvia à figura do andarilho, despojado e exposto.

Com a emergência do street, os discursos veiculados nas revistas de skate (existentes desde a década de 1970) já não se faziam exclusivamente em prol de sua efetivação como um "esporte radical". Para além dos vôos alçados nas pistas de concreto ou madeira, esse novo uso do skate nos espaços urbanos ativava formas de enunciações discursivas até então inexistentes (ou pouco relevantes) nessas publicações, incitando a questionamentos e sentidos que fugiam ao par "esporte" e "radicalidade". 


\section{Criando práticas e representações: o caso do "street skate"}

Para pensar a questão das heterotopias, utilizaremos aqui três revistas de skate publicadas durante a década de 1980 no Brasil: as revistas Yeah!, Overall e Skatin'. Nosso objetivo não é realizar um estudo exaustivo dessas mídias, mas sim identificar o modo como elas passaram a retratar o skate de rua (street skate) que estava nascendo na época.

A revista Yeah! - edição de maio de 1986 - trouxe em sua capa uma manchete sobre o street skate, intitulada: "O skate invade as ruas". Na fotografia, de autoria de Daniel Bourqui, era retratado um skatista saltando sobre uma escada. No interior dessa revista, ficamos sabendo que o skatista se chamava César "Portuga" e que a escada fotografada ficava na cidade do Rio de Janeiro. "O skate invade as ruas" também foi o tema do pôster dessa edição, localizado em suas páginas centrais. Além do pôster, uma matéria intitulada "Pontos Indeterminados" apresentava, em 10 fotografias, a prática do street skate em diversos "pontos" espalhados pelas cidades de São Paulo e alguns em Florianópolis. Acompanhando as imagens, uma série de legendas buscava explicar ao leitor que, diferentemente do skate vertical, que dependia de um half-pipe ("U”) ou de algum outro tipo de pista para acontecer ${ }^{6}$, a prática do street skate podia ser exercida em qualquer lugar e a qualquer hora ${ }^{7}$. Por isso, no meio das imagens que demonstravam skatistas em ação, deslizando e saltando sobre os mais inusitados pontos da arquitetura dessas cidades (como bancos, muros e paredes), havia inúmeras legendas que diziam, por exemplo, que "aproveitar o espaço é antes de tudo uma questão de criatividade", pois "ir à procura de locais skatáveis é uma missão arriscada [...] é descobrir uma nova aventura a cada local encontrado."

Já na segunda edição da revista Overall, também publicada no ano de 1986, havia uma reportagem que apresentava skatistas "horrorizando os obstáculos das

\footnotetext{
${ }^{6}$ Como as pistas que tinham um formato de feijão, chamadas "banks", ou bacia, chamadas "bowl".

${ }^{7}$ Revista Yeah!, no 2, 1986, p. 36. Também localizamos o mesmo discurso na revista Overall, que afirmava ser "o acesso ao street skating o mais fácil possível. As ruas estão aí para serem usadas, a qualquer hora de qualquer dia”. Revista Overall, nº 7, 1987, p. 16.
}

${ }^{8}$ Revista Yeah!, n 2, 1986, p. 37. 
ruas de Sampa". Nesta edição em especial, o street foi o tema principal em uma matéria que recebeu um título bastante irônico ${ }^{10}$ : "Não acordem a cidade... Street Skate" "11. A matéria, escrita por Fábio Bolota (skatista e um dos colaboradores desta edição) se reportava ao street skate da seguinte maneira,

Eu quero mais é asfalto e concreto, para pegar meu skate e sair por aí, gastando minhas rodas, descendo e subindo ladeiras puxado por ônibus, dropar de muros, horrorizar o trânsito, achar transições para uma boa diversão, entrar na contra-mão, subir guias, etc. Por que? Porque nós amamos isto, vivemos disto!!!

Imagine a infinidade de coisas que uma cidade pode ter em suas ruas, postes, carros, guias, shits, bêbados, bitchs, transições, buracos, valas, velhas e muito asfalto. E o que isto significa? Obstáculos?

Talvez sim, para aqueles que não possuem a ousadia de encarar ruas desconhecidas e terrenos inexplorados. Mas para outros, todos esses "obstáculos" se transformam num verdadeiro campo de batalha, em que o objetivo é demonstrar o domínio sobre a arma de ataque: o skate. E o ground de ação: as ruas! ${ }^{12}$

"Horrorizar os obstáculos das ruas", "horrorizar o trânsito" e "entrar na contra-mão" não parecem ser atitudes condizentes ao que geralmente identificamos como "esporte". Se com os campeonatos e o desenvolvimento das pistas, o skate estava sendo associado ao termo "esporte radical", agora, para além dele (mas de modo concomitante) reivindicavam-se certas características que em nada podiam ser comparadas às tradicionais formas de organização esportiva.

\footnotetext{
${ }^{9}$ Revista Overall, no 2, 1986, p. 5.

${ }^{10}$ A ironia se deve ao fato do skate produzir muito barulho ao ser exercido nas ruas, fato que entrava em contradição com o título da matéria, que dizia: "Não acordem a cidade...Street Skate".

${ }^{11}$ Possivelmente este título "Não acordem a cidade" também faça alusão a uma canção de mesmo título da banda de punk rock chamada Inocentes, a qual é citada tanto na Overall quanto na Yeah! e Skatin' como uma das principais influências dos skatistas da época, tendo entrevistas publicadas nessas mídias. A letra da música, transcrita no livro de Helena Wendel Abramo, diz assim "De noite quando a cidade dorme/anjos negros de asas sujas e escuras/saem de suas tocas/e tomam conta das ruas/são os reis da diversão/do ódio e da solidão/não têm esperança/nem de viver nem de vingança/em cada esquina que você passar/em cada beco que você entrar/não se espante/eles vão estar lá/vendem sexo e drogas/roubam ou matam/têm vida curta/não importa o que façam". Apud ABRAMO, Helena Wendel. Cenas Juvenis: punks e darks no espetáculo urbano. São Paulo: Scritta, 1994, p. 102.
}

${ }^{12}$ Revista Overall, n $^{\circ} 4,1986$, p. 16. 
Um outro exemplo nesse sentido podemos encontrar numa matéria especial sobre street skate publicada na edição de junho/julho de 1989 da revista Skatin'. Nesta edição, uma das matérias principais chamava-se "Estritamente street" e tinha como subtítulo: "um modo especial de ver um mundo bastante conhecido: as ruas". Os textos abaixo são de autoria de Luiz Calado, sendo que cada fragmento reproduzido vinha publicado na revista junto a uma fotografia de um skatista explorando bancos, bordas e escadas. Ao lê-los, eles nos ajudam a compreender melhor a formação dessas representações espaciais,

Não foi ele quem planejou aquilo. E não planejaram pensando nele. Aquilo simplesmente está ali. E não poderia ser melhor/ Seus olhos brilham vendo o que ninguém mais vê. Sua mente viaja no que ninguém mais imagina. Seu coração acredita no que ninguém mais crê. E seu corpo vibra com o que ninguém mais sente/ Em busca de emoções verdadeiras, ele foge das regras convencionais, cria novos conceitos e vence seus próprios limites/ Misturando dimensões de tempo e espaço, ele transforma a ilusão de muitos numa realidade para poucos/ As ruas escondem perigos, abrigam incertezas e oferecem desafios. Nas ruas ele mostra coragem, revela precisão e se torna um vencedor. / Entre formas frias e estáticas, ele se torna um ser colorido e móvel/ Enquanto as pessoas se escondem em seus gigantes arranha-céus, ele encontra a liberdade a alguns centímetros do chão/ Mesmo cercado por centenas de quilômetros quadrados de concreto, poucos metros são mais que suficientes para que ele concentre toda sua criatividade e energia. ${ }^{13}$

Nessa revista, seguindo o mesmo tom das outras duas publicações citadas, o skatista era apresentado aos leitores como alguém que "foge das regras convencionais" e, por isso mesmo, "encontra a liberdade". Não é difícil deduzirmos que a prática do street skate era bastante diversa daquela praticada em rampas verticais, pistas construídas em espaços delimitados e organizada nos moldes de um esporte de competição. No street até haveria um "vencedor", como nos diz a citação acima, mas o derrotado não era um oponente (um outro skatista), mas sim os limites dos corpos e dos espaços.

\footnotetext{
${ }^{13}$ Revista Skatin', n. 6, 1989, p. $30-39$.
} 


\section{o "street skate" eo movimento "punk"}

Ao retratarem o street skate em suas páginas essas mídias buscavam outros vieses discursivos que pouco (ou nada) tinham a ver com o esporte ${ }^{14}$. Assim, em uma das passagens da revista Yeah!, por exemplo, localizamos o seguinte trecho de autoria de Paulo Anshowinhas, seu editor,

Eles [os skatistas] não se preocupam com a etiqueta social, nem com o sistema que tentam thes impor. Criam uma anarquia urbana e circulam sem nenhum tipo de autoritarismo. São os filhos do futuro! Não se importam com comentários ou críticas, pois banalidades já estão cansados de ouvir. Eles pensam diferente do Status Quo e se comportam como ta ${ }^{15}$.

Ora, como formar as bases sólidas para o desenvolvimento esportivo de uma "anarquia urbana"? Não seriam anarquia e esporte termos imaginariamente antagônicos? Pois o conceito moderno de esporte ${ }^{16}$ não é algo sempre relacionado ao rendimento físico e ao tempo das provas, que exigem o espaço instituído e o gesto preciso? Em sua organização ele não revelaria sempre "um programa temporal, um calendário especial, com provas regulamentadas e rigorosamente escalonadas ao longo do ano"?

Esporte, destarte, é algo que se pratica com disciplina e respeito às regras estabelecidas, jamais com "anarquia". A questão, portanto, é que havia uma forte relação entre o street skate e as formas de anarquia criadas por um outro movimento juvenil que também estava se desenvolvendo neste mesmo período: o punk $k^{17}$.

No Brasil, o movimento punk teve seus primeiros sinais de vida no final da década de 1970, no contexto da ditadura militar ${ }^{18}$. No entanto, foi somente a

\footnotetext{
${ }^{14}$ Salvo às vezes em que alguns promotores organizavam campeonatos de street skate em locais como ginásios esportivos. Nesses espaços eles fabricavam rampas de madeira e colocavam trilhos para os skatistas deslizarem.

${ }^{15}$ Revista Yeah!, n 2, 1986, p.23.

${ }^{16}$ Para uma discussão sobre a formação do conceito moderno de esporte, ver: MELO, Victor Andrade de. Esporte e Lazer: conceitos: uma introdução histórica. Rio de Janeiro: Apicuri, 2010.

${ }^{17}$ ABRAMO, Helena Wendel. Op. cit., p. 91.

${ }^{18}$ Segundo o historiador Roberto Camargo de Oliveira, foi “em meio à ditadura militar (1964/1985), época de intensa repressão a manifestações culturais, sociais e políticas com teor rebelde/contestador, que surgiram as primeiras bandas nacionais entre 1977 e 1978: Condutores de Cadáver, AI-5
} 
partir do ano de 1982, quando um projeto de abertura política no país já estava em andamento, que esse movimento começou a ter uma maior expressão, sobretudo na cidade de São Paulo. Segundo o historiador Antonio Carlos Brandão,

em 1977 o país recebia apenas algumas informações sobre esse movimento, em sua maioria pela grande imprensa e por discos importados. Eram informações que, geralmente, deixavam a impressão de mais um modismo. O número de punks era pouco representativo. No país, o movimento apenas tomou corpo em 1982, principalmente nas periferias das grandes cidades, apresentando grupos como Lixomania, Inocentes, Olho Seco, Ratos de Porão, entre outros, alheios aos grandes meios de comunicação ${ }^{19}$.

Importante lembrarmos que, nesta época, o modelo de desenvolvimento capitalista adotado pela Ditadura Militar, após os breves anos da euforia do "milagre econômico", começava a resultar numa grave crise financeira. Crise esta que levou o país, ao longo desses anos de transição para a democracia, a conviver com altas taxas de inflação, um enorme endividamento (tanto externo quanto interno) e com uma grande concentração de renda. E embora não haja estudos comparativos sobre a emergência do movimento punk na Inglaterra e no Brasil, existem alguns indícios para pensarmos, como afirmou o historiador Rafael Lopes de Souza, que tanto o punk inglês quanto o brasileiro desenvolveram-se a partir de um quadro de desorganização econômica que "estimulou a união de jovens excluídos dos benefícios sociais em torno de um mesmo movimento" 20 .

Foi neste contexto, marcado por um lado pelo início da abertura política, e por outro pelo agravamento da crise social, que os punks começaram a estruturar mais claramente uma cena musical no país, elaborando festivais e gravações em áudio. Pois, como afirmou Antonio Brandão,

Os punks brasileiros [...] gravaram seu primeiro disco, uma coletânea chamada Grito Suburbano, em 1982, reunindo grupos como Inocentes, Olho Seco e Cólera, pelo selo independente Punk Rock. No mesmo ano, os punks conseguiram realizar o controvertido festival "O Começo do Fim do Mundo" (no

e Restos de Nada". OLIVEIRA, Roberto Camargo. Do punk ao hardcore: elementos para uma história da música popular no Brasil. In Temporalidades (UFMG), vol. 3, n. 1, janeiro/julho de 2011, p. 133.

${ }^{19}$ BRANDÃO, Antonio Carlos. Movimentos culturais de juventude. São Paulo: Moderna, 2004, p. 110.

${ }^{20}$ SOUSA, Rafael Lopes de. Punk: cultura e protesto. São Paulo: Edições Pulsar, 2002, p. 61. 
Sesc Pompéia, em São Paulo), chamando a atenção da polícia e dos meios de comunicação para esse movimento de jovens, em sua maioria, suburbanos ${ }^{21}$.

Embora tenhamos notícias de muitas brigas no interior do movimento punk no início da década de 1980, sobretudo entre os punks de São Paulo e os do ABC paulista, é fato que elas foram gradualmente sendo diluídas ${ }^{22}$. Assim, seria um equívoco interpretarmos tal fenômeno somente pelo viés da violência juvenil, pois para além dele, o movimento é algo intrinsecamente ligado à música, sendo possível afirmar que ele foi uma forma de resistência às expressões musicais em voga no período e, em particular, uma resistência ao rock progressivo - visto como um "desvirtuamento" do rock tradicional. Sobre esse ponto em particular, a antropóloga Janice Caiafa escreveu que no punk rock,

O som é muito simples, e muito rápido. Basicamente percussivo, com vocal violento. Contra a complicação do "rock progressivo" que se fazia na época, o punk rock é o uso imediato do instrumento. Produzir intensidade e lançar um desafio - essa a contundência do punk - e fazer isso com o mínimo. O punk surgiu então num momento em que a extrema complexidade de elaboração e execução fazia do rock uma obra de muitos anos de trabalho (as etapas de progresso e maturação) e muito dinheiro para comprar os mais sofisticados equipamentos ${ }^{23}$.

O que chamamos de punk, portanto, não existe como um movimento social independente da cena musical. Além disso, segundo o pesquisador Craig O'hara, a maioria das letras de punk rock aproximava-se do anarquismo ou eram escritas sob sua influência, e isso significava questionar o conformismo social, a submissão à autoridade e ao governo.

De fato, no Brasil, muitas bandas surgidas na década de 1980 diziamse anarquistas. Evidentemente, nem todos os punks brasileiros tinham tal discernimento, muitos entravam para o movimento ou curtiam as bandas somente pela energia das músicas ou pelo fato de poderem pertencer a um grupo $^{24}$. No

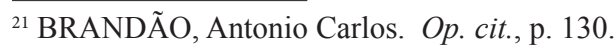

${ }^{22}$ Acerca disso, ver o vídeo-documentário "Botinada: a origem do punk no Brasil”, dirigido por Gastão Moreira e lançado pela ST2 vídeo em 2006.

${ }^{23}$ CAIAFA, Janice. Movimento punk na cidade: a invasão dos bandos sub. Rio de janeiro: Jorge Zahar,1989, p. 9.

${ }^{24}$ Lembramos que, de acordo com Maffesoli, "as matizes da vestimenta, os cabelos multicoloridos e outras manifestações punk servem de cimento. A teatralidade instaura e reafirma a comunidade". 
entanto, como afirmou O'hara, mesmo que muitos punks não fossem versados em história e teoria do anarquismo, havia entre a maioria a "crença formada em torno dos princípios anarquistas de não ter um governo oficial ou governantes"25. Assim, em uma entrevista publicada em janeiro de 1988 pela revista Yeah! com Clemente, vocalista de uma banda punk chamada "Inocentes", por exemplo, o mesmo afirmava que os membros de sua banda eram "absolutamente contra o Fascismo" e que a Anarquia era um ideal com a qual simpatizavam ${ }^{26}$. Além disso, Clemente também dizia ter acompanhado o PT (Partido dos Trabalhadores) desde sua criação por acreditar nele como o partido "menos corrupto de todos" 27 . Ao final da entrevista, Clemente ainda recomendava aos seus leitores que lessem "1984, de George Orwell" 28 .

Com relação ao skate, numa entrevista com a mesma banda Inocentes, publicada na primeira edição da revista Skatin', de 1988, um outro integrante da banda, chamado Tonhão ${ }^{29}$, dizia que "o skate saiu da rua, como a gente", e afirmava que o paralelo existia porque ambos tinham que "fugir da polícia"30. De fato, como apontou o skatista Guto Jimenez, um dos articulistas da revista Yeah!, havia sim uma relação entre o skate e o punk - relação essa que começou nos Estados Unidos e depois também ocorreu no Brasil. Além disso, ele atesta que essa identificação também ajudou na diferenciação entre o skate e o surfe. Segundo seu depoimento,

Nos EUA surgiu o movimento musical do punk hardcore, de música rápida e ignorante, que caiu imediatamente no gosto dos skatistas. Somente uns 5 anos depois é que a surfistada começou a curtir um som mais punk, por assim dizer; antes os surfistas ouviam bandas de hard rock, reggae e os primeiros sons identificados como surf music. O skate punk surgiu pra marcar a diferença entre as tribos ${ }^{31}$.

MAFFESOLI, Michel. O tempo das tribos: o declínio do individualismo nas sociedades pós-modernas. Rio de Janeiro: Forense Universitário, 2006, p. 134.

${ }^{25}$ O’HARA, Craig. A filosofia do punk: mais do que barulho. São Paulo: Radical Livros, 2005, p. 74.

${ }^{26}$ Revista Yeah!, n ${ }^{\text {7 }}$, janeiro de 1988, p. 52.

${ }^{27}$ Idem, p. 52.

${ }^{28}$ Idem.

${ }^{29}$ Tonhão era o baterista da banda.

${ }^{30}$ Revista Skatin', n. 1, 1988, p. 65.

${ }^{31}$ Em entrevista realizada no dia 03/12/2011 (Arquivo do autor). 
Ao analisarmos as revistas supracitadas, podemos observar que essa relação (entre o skate e o punk) se manifestava como um "contágio", isto é, como uma influência do punk tanto na forma como os skatistas de rua apropriavamse da cidade quanto no modo como essa atividade passava a ser retratada por suas mídias especializadas. Frases como "subindo e descendo ladeiras puxados por ônibus, dropar de muros e horrorizar o trânsito", ou ainda, ter a "ousadia de encarar ruas desconhecidas e terrenos inexplorados", indicavam algo de transgressor, rebelde, atitudes similares as que encontramos nas manifestações punk $^{32}$.

A questão é que tanto a Overall quanto a Yeah! e Skatin' traziam seções com comentários sobre a discografia desse gênero musical. "Punk's not dead" era o nome de uma seção da revista Yeah! que comentava os discos de músicos punks. Os LP's tinham títulos sugestivos: "Grito do suburbano", "O começo do fim do mundo", "Crucificados pelo sistema", "Tente mudar o amanhã", "Brigadas de ódio", "Mais podres do que nunca", "Ataque sonoro" etc. Desta forma, ao ler tais publicações, escutar as músicas, informar-se sobre as resenhas dos LP's e irem (eventualmente) aos shows de punk rock, muitos skatistas ficavam cada vez mais familiarizados com as formas de pensar e agir que vinham desse cena musical. Tal influência, contudo, passava a ser praticada nas ruas. Enxergá-las como um "campo de batalha", indica bem a guerra da qual as ruas tornavam-se palco: guerra simbólica, heterotópica, busca por espaços e (des)territorializações.

De certo modo, havia uma semelhança entre a atitude dos skatistas de transitar por locais não projetados para essa prática com a atitude do movimento punk de negar qualquer tipo de imposição social. Pois a partir dessas representações do urbano advindas do street, os skatistas carregavam também um pouco do espírito irreverente do punk, pois ambos questionavam as normas e padrões sociais até então estabelecidos. Nesse sentido, por exemplo, de acordo com um leitor da

\footnotetext{
${ }^{32}$ Em seus estudos sobre tatuagens, a pesquisadora Célia Maria Antonacci Ramos lembrou que os punks "vestiam-se à moda ultrajante para o sistema da época. Jaquetas de couro preto e roupas rasgadas e desbotadas misturavam-se às mutilações corporais, tais como: pequenas queimaduras com tocos de cigarro, escarificações faciais com agulhas, piercing no nariz, lábios e peito, e tatuagens pelo corpo todo. Em suas apresentações encenavam rituais de provocação, dança transe regada a álcool e drogas [...] Tal provocação ao sistema estabelecido mais de uma vez foi interrompida por policiais”. RAMOS, Célia Maria Antonacci. Teorias da tatuagem: corpo tatuado. Florianópolis: UDESC, 2001, p. 124.
} 
Yeah!, chamado Sérgio Borin Del Vale, de Atibaia/SP, a analogia entre o street skate e o punk estava no modo como os skatistas representavam e se apropriavam da cidade. Em suas palavras, ele dizia,

O skate apareceu como um desafio à paisagem urbana e hoje [maio de 1986] se estendeu por todos os cantos do país. Acho o skate o esporte mais punk, pois andar de skate é uma anarquia saudável. Você se sente dono da cidade. Cria em cima daquilo que já foi criado. Enfim, inverte tudo o que está parado ${ }^{33}$.

Palco de manobras e aventuras do skate, a cidade foi sendo gradualmente conquistada, interpretada e apropriada. E se as pistas levaram alguns skatistas a trilharem os rumos do "esporte", ou mais especificamente os rumos do "esporte radical", as "aventuras" do street demonstravam que também havia outros caminhos que poderiam ser explorados. Pois mesmo que os skatistas (como na citação acima) ainda recorressem ao conceito de esporte para caracterizar essa prática, o desconforto era logo amenizado por sua adjetivação como algo além ou aquém de um esporte. Neste caso, o "skate era o esporte mais punk". Assim, como apontado pela pesquisadora Carmen Lúcia Soares, devido à existência dessa mentalidade esportiva que a quase tudo permeia e contamina, tornava-se difícil - até mesmo para os próprios skatistas - reconhecerem-se em registros alheios à "cultura do esporte" 34 .

\section{Considerações finais}

Se no caso do skate praticado em pistas com rampas verticais ("U") é menos problemático a ampliação do conceito de esporte para caracterizá-lo, a denominação do street skate como um esporte choca-se com seu uso irreverente e transgressor nas ruas dos grandes e médios centros urbanos. Nesses espaços da cidade não havia competição, não havia um tempo cronometrado e nem juízes. Neles, o que contava era a liberdade para criar, para passar por cima de obstáculos imaginados, saltar sobre bancos, escadas, enfim, escorregar sobre as dobras da matéria. O skate de rua, neste sentido, manifestava-se de maneira informal e não através da formalidade esportiva (cronômetros, juízes, equipes etc). Tratava-

\footnotetext{
${ }^{33}$ Revista Yeah! ano 1, n. 2, maio de 1986, p. 10.

${ }^{34}$ SOARES, Carmen lúcia. Práticas corporais: invençãode pedagogias? In: SILVA, Ana Márcia; DAMIANI, Iara Regina (Orgs.). Práticas corporais. Florianópolis: nauemblu Ciência \& Arte, 2005, p. 48.
} 
se de novas experiências juvenis, heterotópicas, que buscavam singularizar as vivências do cotidiano ao explorarem "outros espaços", inventando maneiras de ser onde o lúdico tinha - quase sempre - um lugar especial.

Quem poderia identificar skatistas nas ruas como "esportistas"? Afinal, eles corriam da polícia, muitos escutavam punk rock e, de modo algum, utilizavam uniformes de equipe tais como os jogadores de futebol, por exemplo. "Em 1981 já usavam pulseiras de rebite, em 1982 pintavam os cabelos de verde ou roxo" ${ }^{35}$. O skatista paulistano apelidado como "Pois é!", por exemplo, "catava o que via pela frente e transformava em pulseira. Cadarços, plásticos, arames, fios elétricos, varal... E como ele era streeteiro e a rua era um prato cheio, sempre aparecia com braçadeiras enormes para andar de skate no Parque do Ibirapuera", recorda a escritora Cecília Gonçalves, que viveu o período junto aos skatistas de São Paulo ${ }^{36}$.

Ao observarmos a emergência do street skate durante a década de 1980, portanto, encontramos um exemplo concreto de heterotopia! Pois andar de skate na cidade era desenhar um novo uso do tempo livre, inventar algum estilo de vida que estivesse sempre mais próximo da diversão e também da rebeldia. Era conquistar, dessa forma, novos modos de subjetividade, de leituras do espaço e de inserção mesmo nesse espaço. E isso implicava uma disponibilidade sempre presente para o desejo, para um tempo de satisfação, de invenção de si e, certamente, de "re-criação" 37 .

${ }^{35}$ GONÇALVES, Cecília Moisés. Eu não era feliz e sabia. In: BRITO, Eduardo (Org.). $A$ onda dura: 3 décadas de skate no Brasil. São Paulo: Parada Inglesa, 2000, p. 92.

36 Idem.

${ }^{37}$ Devemos a utilização do termo a Alain Corbin. CORBIN, Alain. A história dos tempos livres. In CORBIN, Alain (org.). História dos tempos livres: o advento do lazer. Lisboa: Teorema, 2001, p. 14 